\title{
Option Pricing under Randomised GBM Models
}

\author{
Giuseppe Campolieti ${ }^{a}$, Hiromichi Kato ${ }^{b}$, Roman Makarov ${ }^{c}$ \\ Wilfrid Laurier University, Waterloo, Ontario, Canada \\ ahttps://orcid.org/0000-0002-6316-7313; ${ }^{b}$ https://orcid.org/0000-0002-3724-2404 \\ chttps://orcid.org/0000-0002-0935-9445
}

\begin{abstract}
By employing a randomisation procedure on the variance parameter of the standard geometric Brownian motion (GBM) model, we construct new families of analytically tractable asset pricing models. In particular, we develop two explicit families of processes that are respectively referred to as the randomised gamma $(G)$ and randomised inverse gamma (IG) models, both characterised by a shape and scale parameter. Both models admit relatively simple closed-form analytical expressions for the transition density and the no-arbitrage prices of standard European-style options whose Black-Scholes implied volatilities exhibit symmetric smiles in the log-forward moneyness. Surprisingly, for integer-valued shape parameter and arbitrary positive real scale parameter, the analytical option pricing formulas involve only elementary functions and are even more straightforward than the standard (constant volatility) Black-Scholes (GBM) pricing formulas. Moreover, we show some interesting characteristics of the risk-neutral transition densities of the randomised G and IG models, both exhibiting fat tails. In fact, the randomised IG density only has finite moments of the order less than or equal to one. In contrast, the randomised $G$ density has a finite first moment with finite higher moments depending on the time-to-maturity and its scale parameter. We show how the randomised $\mathrm{G}$ and IG models are efficiently and accurately calibrated to market equity option data, having pronounced implied volatility smiles across several strikes and maturities. We also calibrate the same option data to the wellknown SABR (Stochastic Alpha Beta Rho) model.

Keywords: static randomisation; pricing European-style options; Black-Scholes implied volatility; calibration; randomised GBM models; SABR model
\end{abstract}

For citation: Campolieti, G., Kato, H., \& Makarov, R. (2021). Option pricing under randomised GBM models. Review of Business and Economics Studies, 9(3),7-26. DOI: 10.26794/2308-944X-2021-9-3-7-26

\section{Оценка стоимости опционов} для рандомизированных моделей
геометрического броуновского движения

\author{
Джузеппе Камполиети, Хиромичи Като, Роман Макаров \\ Университет Уилфрида Лорье, Ватерлоо, Онтарио, Канада
}

\begin{abstract}
АННОТАЦИЯ
Используя процедуру рандомизации дисперсии стандартной модели геометрического Броунского движения (ГБД), авторы построили новые семейства аналитически решаемых моделей ценообразования финансовых активов. В частности, были разработаны два семейства процессов, а именно модели - рандомизированная гамма (Г) и рандомизированная обратная гамма (ОГ), которые характеризуются параметрами формы и масштаба. Обе модели допускают довольно простые аналитические выражения для плотности перехода и безарбитражной цены стандартных европейских
\end{abstract}

(c) Giuseppe Campolieti, Hiromichi Kato, Roman Makarov, 2021 
опционов. Волатильность Блэка-Шоулза проявляет симметричную «улыбку» для логарифмически форвардной денежности. Примечательно, но для целых значений параметра формы и произвольного положительного параметра масштаба аналитические формулы ценообразования вариантов включают только элементарные функции и даже являются проще стандартных (для постоянной волатильности) формул ценообразования Блэка-Шоулза (модель ГБД). В статье даны характеристики риск-нейтральной плотностей перехода для рандомизированных моделей Ги ОГ, которые демонстрируют «тяжелые хвосты». Рандомизированные плотности для модели ОГ имеют только конечные моменты порядка меньше или равные одному, в то время как рандомизированная плотность для модели Гимеет конечный первый момент и конечные моменты более высокого порядка в зависимости от срока погашения опциона и параметра масштаба. Показано, как рандомизированные модели Ги ОГ могут быть эффективно и точно откалиброваны для рыночных значений опционов, демонстрирующих «улыбку» волатильности для различных цен исполнения и сроков погашения. Откалибровка проведена с помощью модели SABR (Stochastic Alpha Beta Rho). Проведено сравнение этих моделей.

Ключевые слова: статическая рандомизация; ценообразование опционов европейского стиля; подразумеваемая волатильность Блэка-Шоулза; калибровка; рандомизированные модели GBM; модель SABR

\section{Introduction}

Mathematicians have developed stochastic models to value options. The geometric Brownian motion (GBM) model is known as one of the simplest continuous-time models that admit analytical closed-form formulas for pricing various options (Black \& Scholes, 1973). The GBM model is a complete market model where risks can be perfectly hedged. A significant limitation is that there is a discrepancy between anticipated Black-Scholes (BS) prices and the market option prices since the model fails to capture price movements for extreme events (MacBeth \& Merville, 1979). Local volatility diffusion models (also known as state-dependent volatility models) are more flexible continuous-time models known for describing the behaviour of implied volatility smile and skew patterns observed in a marketplace. Local volatility diffusion models are also complete market models like the GBM model. In fact, the (one-dimensional) GBM model is simply a local volatility model with constant local volatility.

In some cases, nonlinear local volatility models admit closed-form formulas for pricing various options. Families of local volatility diffusion models that can be analytically solved in closed form have been developed in several papers, see, e.g., Albanese, Campolieti, et al. (2001) and Campolieti and Makarov (2012). They are obtained by applying the "diffusion canonical transformation" to solvable underlying diffusions such as the Bessel, Cox-Ingersoll-Ross and OrnsteinUhlenbeck processes. These models have been shown to calibrate quite well to equity and FX options. One drawback of local volatility diffusion models is the inherent perfect correlation between the underlying asset price and the volatility. In some cases, this contradicts the empirical evidence that they should have an imperfect negative correlation (Rubinstein, 1985).

The stock market is incomplete in many situations as traders cannot use options for hedging all the risks. Stochastic volatility models are incomplete and assume that volatility is a random process. We can make the movements of the underlying asset price and the volatility to be negatively correlated. A first example is the Hull and White stochastic volatility model. Hull and White (1987) derived the closed-form pricing formulas for European vanilla options under their model with zero correlation. They are obtained by averaging the BS prices over the integrated squared instantaneous volatility process. Theoretical results of implied volatility under the GBM model with stochastic volatility are given in Renault \& Touzi's paper (1996). They have shown that an implied volatility surface is an even function of the log-forward moneyness and necessarily produces a smile effect under the models with zero correlation. Thus, these models may be used to calibrate to option price market data.

A second example is the Heston model. Heston (1993) successfully applied the Fourier transform method to evaluate European vanilla options with an arbitrary correlation between the asset price and the volatility. He also showed that the distribution of asset returns is asymmetric. Also, he found that when the marginal distributions of the asset returns and the volatility are negatively 
skewed. Moreover, the BS out-of-the-money (OTM) option prices are negatively biased (i.e., BS OTM option prices are usually smaller when compared to market prices). BS in-the-money (ITM) option prices are positively biased.

A third example is the SABR model introduced by Hagan et al. (2002). The implied volatility curve captured by the SABR model gives consistency with the observed marketplace in dynamics. Other examples are regime-switching models. Bollen demonstrated that the model with two regimes could produce pronounced symmetric smiles in the log-forward moneyness, giving consistency with the higher BS pricing errors for shorter maturities (Bollen, 1998).

This paper constructs new pricing models with randomised volatility, where underlying asset price distributions exhibit fat tails and admit simple closed-form analytical expressions for standard European-style option prices. In particular, we assume that: 1) a unique risk-neutral pricing measure exists (in advance), 2) the underlying asset price processes have a finite first moment but possibly infinite higher moments, 3) there are no correlations between the asset prices and their volatility, and 4) the volatility (squared volatility) coefficient is a random variable with known probability density function (PDF). The assumptions 1) and 2) are based on the Put-Call Parity methodology in Taleb (2015). This methodology neglects the strong (but surreal) assumptions from the dynamic hedging argument and exhibits better practical phenomena in financial markets. The assumptions 1)-4) allow for deriving closedform expressions (under our new pricing models) by taking a mathematics expectation under diffusion models over the underlying probability distribution for the volatility. Our methodology for computing option prices is closely related to the Bayesian framework in the GBM model studied by Darsinos and Satchell (2007). They considered randomising the volatility where the variance follows the inverse gamma distribution. They were successful in deriving analytically closed-form expressions for the joint PDF of the asset price and the volatility, as well as the marginal PDF of the asset price. However, they could not determine the call pricing formulas analytically, and the option prices could only be obtained numerically.

This paper is organised as follows. Section 2 proposes a general theory of static randomisation under the GBM model, including the almost everywhere (a.e.) existence of transition probability density functions (PDF) of newly constructed asset price processes. We then derive the transition PDFs of the asset price process with static randomisation of the parameter under two families of static randomisation, namely the gamma $(G)$ and the inverse gamma (IG) randomisation. Section 3 states the main results of this paper, including the closed-form expressions of a European vanilla call option and the characteristics of shapes of the implied volatility. In Section 4, we conduct our numerical experiments pertaining to model calibrations to market option data. Finally, we state some concluding remarks with some discussions of future applications.

\section{Randomised GBM Models and their Characteristics}

Let $\left(\Omega, \mathcal{F}, \widetilde{\mathbb{P}},\left\{\mathcal{F}_{t}\right\}_{t \geq 0}\right)$ be some fixed filtered (riskneutral) probability space where $\left\{\mathcal{F}_{t}\right\}_{t \geq 0}$ is the natural filtration generated by the $\widetilde{\mathbb{P}}-\mathrm{BM}$. Assume a two-asset economy where the risky asset price (diffusion) process $\left\{S_{t}\right\}_{t \geq 0}$ follows a GBM with stochastic differential equation (SDE):

$$
\frac{d S_{t}}{S_{t}}=r d t+\sqrt{v} d \widetilde{W}_{t} ; \quad S_{0}>0
$$

where $r$ is the constant risk-free rate, $v$ is a constant variance and $\left\{\widetilde{W}_{t}\right\}_{t \geq 0}$ is a standard $\widetilde{\mathbb{P}}$-BM (i.e., Brownian motion under the riskneutral measure with a bank account as numéraire). The (risk-neutral) transition PDF for this process (for a given variance $v$ ) is time-homogeneous, depending on the time difference $\tau \equiv T-t$ :

$$
\begin{gathered}
\widetilde{\mathbb{P}}_{t, S}\left(S_{T} \in d y\right) \equiv \widetilde{\mathbb{P}}\left(S_{T} \in d y \mid S_{t}=S\right)= \\
=\frac{1}{y \sqrt{2 \pi v \tau}} e^{-\left(x+\frac{1}{2} v \tau\right)^{2} / 2 v \tau} d y ; \quad S, y>0, \tau>0,
\end{gathered}
$$

where $x=\ln (y / S)-r \tau$. We now consider randomising the parameter $v$ by introducing the random variable $\mathcal{V}$ to distinguish it from the parameter $v$. Then, we can formulate the pricing function for a standard European-style option with payoff function $\Lambda$ by:

$V_{\mathcal{V}}(\tau, S)=e^{-r \tau} \int_{\Omega_{\mathcal{V}}} \widetilde{\mathbb{E}}_{t, S}\left[\Lambda\left(S_{T}\right)\right] \mu_{\mathcal{V}}(d v), \quad \tau=T-t .(2)$ 
Note that $V_{\mathcal{V}}$ denotes the pricing function for a given choice of the random variable $\mathcal{V}$ on a sample space $\Omega_{\mathcal{V}} \subset \mathbb{R}_{+}$, where $\mu_{\mathcal{V}}$ is a probability measure for $\mathcal{V} .{ }^{1}$ In the case of an absolutely continuous random variable $\mathcal{V}$ we have $\mu_{\mathcal{V}}(d v)=\mu_{\mathcal{v}}(v) d v$ with PDF $\mu_{\mathcal{V}}(v)$. The (marginal) transition PDF for the asset price process with randomised volatility (the randomised GBM process), denoted by $\left\{S_{t}^{\mathcal{V}}\right\}_{t \geq 0}$ is defined for fixed $\tau, S>0$ as: ${ }^{2}$

$$
\widetilde{\mathbb{P}}_{t, S}\left(S_{T}^{\mathcal{V}} \in d y\right) \equiv \int_{\Omega_{\mathcal{V}}} \widetilde{\mathbb{P}}_{t, S}\left(S_{T} \in d y\right) \mu_{\mathcal{V}}(d v)
$$

We can easily show that the transition PDF integrates to one:

$$
\int_{0}^{\infty} \widetilde{\mathbb{P}}_{t, S}\left(S_{T}^{\mathcal{V}} \in d y\right)=\int_{\Omega_{\mathcal{V}}}\left(\int_{0}^{\infty} \widetilde{\mathbb{P}}_{t, S}\left(S_{T} \in d y\right)\right) \mu_{\mathcal{V}}(d v)=1
$$

By a simple application of Fubini's theorem, the transition PDF for $\left\{S_{t}^{\mathcal{V}}\right\}_{t \geq 0}$ is well-defined (a.e.) for every fixed $\tau, S>0$. We can easily show that the discounted randomised process $\left\{e^{-r t} S_{t}^{\mathcal{V}}\right\}_{t \geq 0}$ is a $\widetilde{\mathbb{P}}$-martingale process ${ }^{3}$

$$
\widetilde{\mathbb{E}}_{t, S}\left[S_{T}^{\mathcal{V}}\right] \equiv \widetilde{\mathbb{E}}\left[S_{T}^{\mathcal{V}} \mid S_{t}^{\mathcal{V}}=S\right]=S e^{r \tau}
$$

In what follows, we specify the distribution of $\mathcal{V}$ in two separate ways: as a gamma random variable and as an inverse gamma random variable.

We now look at the transition PDF for the randomised asset price process under the gamma randomisation (the randomised G process), denoted by $\left\{S_{t}^{G(\theta, \lambda)}\right\}_{t \geq 0}$, where $\mathcal{V}$ follows the gamma distribution with shape parameter $\theta$ and scale parameter $\lambda$ (i.e., $\mathcal{V} \sim G(\theta, \lambda)$ ). The PDF of $\mathcal{V}$ is

$$
\mu_{G(\theta, \lambda)}(d v)=\frac{1}{\lambda^{\theta} \Gamma(\theta)} v^{\theta-1} e^{-v / \lambda} d v ; \quad \theta, \lambda>0, \quad \Omega_{G(\theta, \lambda)}=\mathbb{R}_{+},
$$

where $\Gamma(\theta)=\int_{0}^{\infty} t^{\theta-1} e^{-t} d t$ is the gamma function. We state a useful integral formula (see Prudnikov, Brychkov, \& Marichev, 1986, Eq. 2.3.16.1):

$$
\int_{0}^{\infty} v^{r-1} e^{-p v-q / v} d v=2\left(\frac{q}{p}\right)^{r / 2} \mathrm{~K}_{r}(2 \sqrt{p q}) ; \quad r \in \mathbb{R}, \quad p, q>0,
$$

where $\mathrm{K}_{v}$ is the modified Bessel function of the second kind of order $v$. It gives the analytical expression for the transition PDF for $\left\{S_{t}^{G(\theta, \lambda)}\right\}_{t \geq 0}$ :

$$
\widetilde{\mathbb{P}}_{t, S}\left(S_{T}^{G(\theta, \lambda)} \in d y\right)=\frac{e^{-x / 2}}{y \sqrt{\pi} \Gamma(\theta)}\left(\frac{2}{\lambda \tau}\right)^{\theta}\left(\frac{\lambda \tau x^{2}}{8+\lambda \tau}\right)^{\theta / 2-1 / 4} \mathrm{~K}_{\theta-1 / 2}\left(\frac{|x|}{2} \frac{\sqrt{8+\lambda \tau}}{\sqrt{\lambda \tau}}\right) d y
$$

${ }^{1}$ One may think that $\mathcal{V}$ is a random variable on $(\Omega, \mathcal{F}, \widetilde{\mathbb{P}})$ where $\Omega_{\mathcal{V}}$ is the range of $\mathcal{V}$ and $\mu_{\mathcal{V}}$ is the distribution measure. ${ }^{2}$ Note that $\widetilde{\mathbb{P}}_{t, S}\left(S_{T}^{\mathcal{V}} \in d y\right) \equiv \tilde{p}_{\mathcal{V}}(\tau ; S, y) d y$, where $\tau=T-t$ and $\tilde{p}(\tau ; S, y) \equiv \tilde{p}(\tau ; S, y \mid v)$ is the transition PDF (in (1)) of the GBM process for a given volatility parameter value $v$. Hence,

$\frac{\widetilde{\mathbb{P}}_{t, s}\left(S_{T}^{\mathcal{V}} \in d y\right)}{d y} \equiv \tilde{p}_{\mathcal{V}}(\tau ; S, y)=\int_{\Omega_{\mathcal{V}}} \tilde{p}(\tau ; S, y \mid v) \mu_{\mathcal{V}}(d v)$ is the transition PDF of the randomized asset price process $\left\{S_{t}^{\mathcal{V}}\right\}_{t \geq 0}$

${ }^{3}$ Recall that the discounted asset price process under the GBM model $\left\{e^{-r t} S_{t}\right\}_{t \geq 0}$ is a $\widetilde{\mathbb{P}}$-martingale process. Here an underlying filtered probability space for the randomized process is $\left(\Omega, \mathcal{F}, \widetilde{\mathbb{P}},\left\{\mathcal{F}_{t}^{\mathcal{V}}\right\}_{t \geq 0}\right)$ where $\mathcal{F}_{t}^{\mathcal{V}} \equiv \sigma\left(S_{u}^{\mathcal{V}}, 0 \leq u \leq t\right)$. 
Where $x=\ln (y / S)-r \tau$. Note that for $\theta=n \in \mathbb{N}$, the transition PDF can be represented by elementary functions. The asymptotic behaviours of the transition PDF at the endpoints are:

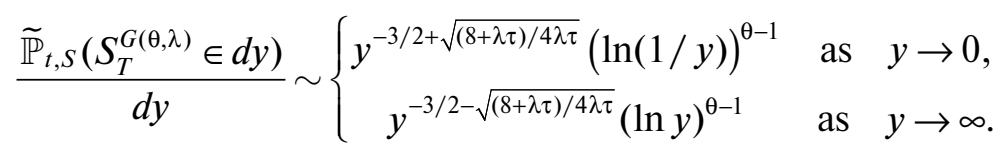

Based on these asymptotic expressions, we conclude that the $\alpha$-moment of the randomised G process:

$$
\widetilde{\mathbb{E}}_{t, S}\left[\left(S_{T}^{G(\theta, \lambda)}\right)^{\alpha}\right] \equiv \int_{0}^{\infty} y^{\alpha} \widetilde{\mathbb{P}}_{t, S}\left(S_{T}^{G(\theta, \lambda)} \in d y\right)<\infty \quad \text { iff }\left|\alpha-\frac{1}{2}\right|<\sqrt{\frac{8+\lambda \tau}{4 \lambda \tau}} .
$$

It implies the first moment exists, but the second moment exists iff $\lambda \tau<1$. Furthermore, we have an explicit formula for the second moment:

$$
\widetilde{\mathbb{E}}_{t, S}\left[\left(S_{T}^{G(\theta, \lambda)}\right)^{2}\right]=S^{2} e^{2 r \tau}(1-\lambda \tau)^{-\theta} ; \text { for } \lambda \tau<1 .
$$

Let us now consider the transition PDF for the asset price process under the inverse gamma randomisation (the randomised IG process), denoted by $\left\{S_{t}^{I G(\theta, \lambda)}\right\}_{t \geq 0}$. Assume that $\mathcal{V}$ follows the inverse gamma distribution with shape parameter $\theta$ and scale parameter $\lambda$ (i.e., $\mathcal{V} \sim I G(\theta, \lambda)$ ). The PDF of $\mathcal{V}$ is

$$
\mu_{I G(\theta, \lambda)}(d v)=\frac{\lambda^{\theta}}{\Gamma(\theta)}\left(\frac{1}{v}\right)^{\theta+1} e^{-\lambda / v} d v ; \quad \theta, \lambda>0, \quad \Omega_{I G(\theta, \lambda)}=\mathbb{R}_{+} .
$$

By using the integral identity in (4) we obtain the transition PDF for $\left\{S_{t}^{I G(\theta, \lambda)}\right\}_{t \geq 0}$ :

$$
\widetilde{\mathbb{P}}_{t, S}\left(S_{T}^{I G(\theta, \lambda)} \in d y\right)=\frac{e^{-x / 2}}{y \sqrt{\pi} \Gamma(\theta)}\left(\frac{\lambda \tau}{2}\right)^{\theta}\left(x^{2}+2 \lambda \tau\right)^{-\theta / 2-1 / 4} \mathrm{~K}_{\theta+1 / 2}\left(\frac{\sqrt{x^{2}+2 \lambda \tau}}{2}\right) d y,
$$

where $x=\ln (y / S)-r \tau$. The asymptotics of the transition PDF are now as follows:

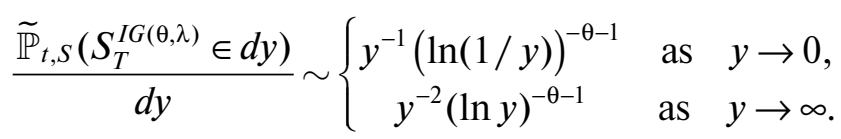

These two asymptotics give

$$
\widetilde{\mathbb{E}}_{t, S}\left[\left(S_{T}^{G(\theta, \lambda)}\right)^{\alpha}\right]<\infty \quad \text { iff } \quad 0 \leq \alpha \leq 1 .
$$

We can see from Figures 1 and 2 that the GBM has the thinnest tail among the three models for $\theta=1,2$. The left plot in Figure 1 shows that for $\theta=1$, the randomised $G$ process has a thinner tail than the randomised IG process for $\theta=1$. The randomised $G$ process appears to have the thickest tail among the three when $\theta=2$, but eventually, the randomised $G$ process tails off faster than the randomised IG process, as shown at the right plot in Figure 2. It is interesting to see that the PDF of the randomised $\mathrm{G}$ process is uniform for $y \leq S e^{r \tau}$ at the right plot in Figure 1. We can also observe that the PDF of the randomised G process is not differentiable at $y=S e^{r \tau}$ since $\mathrm{K}_{v}(z)$ is not differentiable at $z=0$. 


\section{Main Results}

The conditional risk-neutral probability that the randomised asset price process is above the strike $K$ at a time $T$ can be written as elementary analytical functions for $\theta=n \in \mathbb{N}$. ${ }^{4}$ The reader may refer to Appendix 6 for the details. It helps us obtain analytical pricing formulas for European vanilla options. We will illustrate it in this section. The price of a European vanilla call option, denoted by $C_{\mathcal{V}}(\tau, S ; K, r)$, can be written in terms of $\widetilde{\mathbb{P}}_{t, S}$ and $\widehat{\mathbb{P}}_{t, S}$. Here $\widehat{\mathbb{P}}_{t, S} \equiv \widetilde{\mathbb{P}}_{t, S}^{(S)}$ is an equivalent martingale measure with the original asset (e.g., stock) price process $\left\{S_{t}\right\}_{t \geq 0}$ as the numéraire. We have

$$
\widehat{C}_{\mathcal{V}}(\tau, m) \equiv \frac{C_{\mathcal{V}}(\tau, S ; K, r)}{S}=\widehat{\mathbb{P}}_{t, S}\left(S_{T}^{\mathcal{V}}>K\right)-e^{-m} \widetilde{\mathbb{P}}_{t, S}\left(S_{T}^{\mathcal{V}}>K\right)
$$

where $t$ is the current time, $T$ is the expiry time, $\tau=T-t$ is the time to maturity and $m \equiv \ln (S / K)+r \tau$ is the $\log$-forward moneyness. ${ }^{5}$ For the randomised $G$ process with $\theta=n \in \mathbb{N}$, we have (call price divided by the spot $S$ ):

$$
\begin{aligned}
& \widehat{C}_{G(n, \lambda)}(\tau, m)=\left(1-e^{-m}\right)^{+}+\frac{\sqrt{|m|}}{\sqrt{\pi}}\left(\frac{\lambda \tau}{8+\lambda \tau}\right)^{1 / 4} e^{-m / 2} \\
& \times \sum_{k=0}^{n-1} \frac{1}{k !}\left(\frac{2|m|}{\sqrt{\lambda \tau} \sqrt{8+\lambda \tau}}\right)^{k} \mathrm{~K}_{k+1 / 2}\left(\frac{|m| \frac{\sqrt{8+\lambda \tau}}{2}}{\sqrt{\lambda \tau}}\right),
\end{aligned}
$$

where $(x)^{+} \equiv \max \{x, 0\}$. For the randomised IG process with $\theta=n \in \mathbb{N}$, we have

$$
\widehat{C}_{I G(n, \lambda)}(\tau, m)=1-\frac{\left(m^{2}+2 \lambda \tau\right)^{1 / 4}}{\sqrt{\pi}} e^{-m / 2} \sum_{k=0}^{n-1} \frac{1}{k !}\left(\frac{\lambda \tau}{2 \sqrt{m^{2}+2 \lambda \tau}}\right)^{k} \mathrm{~K}_{k-1 / 2}\left(\frac{\sqrt{m^{2}+2 \lambda \tau}}{2}\right) .
$$

We derive general formulas for the main Greeks of a European vanilla call option under randomisation. The general formulas are summarised in Table 1.

It can be shown that the option prices in (6) and (7) retain the symmetry property (see Renault \& Touzi, 1996, Prop. 3.1),

$$
\widehat{C}_{\mathcal{V}}(\tau, m)=\left(1-e^{-m}\right)+e^{-m} \widehat{C}_{\mathcal{V}}(\tau,-m),
$$

and exhibit symmetric smiles in the BS implied volatility. In Figure 3, we can see that for given $\lambda>0$, $\tau>0$ and log-forward moneyness $m$, the BS implied volatility is increasing in $\theta$, and deep in- (and out-) of-the-money option (i.e., large values of $m$ in absolute term) prices are more sensitive to the parameter $\theta$ than near in- (and out-) of-the-money option (i.e., small vale of $m$ in absolute term) prices. In Figure 4, we can see that for given $\lambda>0, \tau>0$ and log-forward moneyness $m$, the BS implied volatility is decreasing in $\theta$, and deep in- (and out-) of-the-money option prices are less sensitive to the parameter $\theta$ than near in- (and out-) of-the-money options. Both figures show symmetric smile effects. We can also see that the BS implied volatility under the gamma randomisation exhibits the V-shaped (i.e., locally concave) smile. In contrast, the BS implied volatility under the inverse gamma randomisation displays the U-shaped (i.e., locally convex) smile. We will show in the next section that the inverse gamma randomisation model calibrates well to some U-shaped market volatility. Hence, it may be helpful for practitioners to employ this model. However, the gamma randomisation model does not commonly fit well as we rarely see market volatility with concave smiles in practice.

\footnotetext{
${ }^{4}$ For $\theta \notin \mathbb{N}$, we can derive the at-the-money forward (ATMF) option prices in closed-form in terms of the hypergeometric functions. The reader may refer to Appendix 7 for the details.
}

${ }^{5}$ Throughout, we denote $m \equiv m(S, K, \tau)=\ln (S / K)+r \tau$ to avoid clutter. 


\section{Numerical Example}

In this section, we calibrate our models to some market option data. We extracted the market data for the Coca-Cola European call options with spot time on April 2, 2019. The market data contains 354 sample data points with 15 distinct values of the maturity time. The market volatility in the data set exhibits pronounced smiles across different strikes for short times to maturity and skewed smiles for long times to maturity. We decided to compare the performance of the new models with the SABR model because the latter admits a closed-form yet simple celebrated formula for approximate implied volatility. We calibrated the models to the market data among classes consisting of all observations with the same maturity times because the SABR model calibrates well at a single maturity but does not calibrate well at multiple maturities ( $\mathrm{Wu}, 2012)$. The summary of the market data used here you can found in Table 2. The reader may refer to Tables 3, 4, 5 and Figures 5, 6, 7, 8 for the results.

Suppose that $V_{i}^{*}, \Sigma_{i}^{*}$ are the observed market option price and market volatility respectively for $i=1, \ldots, N_{\tau}$ where $N_{\tau}=\# \mathcal{S}_{\tau}$ is the number of observations with maturity time $\tau$, and $\tau_{i}, K_{i}$ are the corresponding maturity time and strike price. Define $T=\left\{\tau_{i}: i=1, \ldots, N\right\}$ as the collection of maturity times in the data set arranged in increasing order. Let $\mathcal{S}_{\tau}=\left\{i \mid \tau_{i}=\tau \in T\right\}$ be the collection of observations with maturity time $\tau \in T$. For each $\tau$, we use the usual root mean squared error (RMSE) as a loss function $L(\theta, \lambda)$ for the model calibration under the gamma and the inverse gamma randomisation:

$$
L_{\tau}(\theta, \lambda)=\sqrt{\frac{\sum_{i \in \mathcal{S}_{\tau}\left(V\left(\tau_{i}, S ; K_{i}\right)-V_{i}^{*}\right)^{2}}}{N_{\tau}}} ; \quad \tau \in T,
$$

where $N_{\tau}=\# \mathcal{S}_{\tau}$ is the number of observations with maturity time $\tau$, and $\tau_{i}, K_{i}$ are the corresponding maturity time and strike price. Alternatively, for the SABR model, we use a formula from Hagan et al. (2002), denoted by $\sigma_{S A B R}$, to find optimal values of parameters that minimise the difference between the corresponding BS implied volatility and the market volatility in the RMSE sense. Hence, the loss function for the SABR model calibration is:

$$
L_{\tau}(\alpha, \beta, \sigma, \rho)=\sqrt{\frac{\sum_{i \in \mathcal{S}_{\tau}}\left(\sigma_{\mathrm{SABR}}\left(\tau_{i}, S, \sigma ; K_{i}\right)-\Sigma_{i}^{*}\right)^{2}}{N_{\tau}}} ; \tau \in T,
$$

For the SABR model parameters, we attempted to find optimal values for the parameters $(\alpha, \sigma, \rho) \equiv(\alpha(\beta), \sigma(\beta), \rho(\beta))$ across different values of $\beta \in[-1,0]$, and find the optimal value of $\beta$ by comparing the associated RMSEs. ${ }^{6}$ We found that $\beta=-1$ gave the lowest RMSE.

Based on Tables 3, 4, and 5, we found that: the inverse gamma randomisation performs better than the gamma randomisation because the RMSE is smaller for fixed $\tau$. Figures 5, 6, 7, and 8 suggest that the inverse gamma randomisation performs quite well for short maturity times, and the SABR model fits almost perfectly.

\section{Conclusion}

In this paper, we constructed the randomised GBM processes under the gamma and the inverse gamma randomisation, namely the randomised $\mathrm{G}$ and IG processes. We observed that both processes had thicker tails than the GBM process, and the randomised IG process had the heaviest tails among the three. We obtained explicit no-arbitrage pricing formulas for European vanilla call options with

\footnotetext{
${ }^{6}$ In our data set, we saw that $\beta$ was not a robust parameter since the optimal value for $\beta$ varies with different initial values of $\beta$. So we used the calibration method in Hagan et al. (2002) to find $\beta$ in advance. There are different approaches for the SABR model calibration, see e.g., West (2005).
} 
integer-valued shape parameter and ATMF option prices with real-valued shape parameter. Surprisingly, the pricing formulas presented in this paper are even simpler than the classical GBM model as they are expressed as elementary analytical functions. The option prices were also obtained numerically in an efficient manner. The European-style option prices under the new processes exhibit symmetric smiles in the log-forward moneyness. We calibrated the randomised GBM models and the SABR model to the actual market option data set from Coca-Co- la. We found that the inverse gamma randomisation fitted well, especially for short maturity times.

Further applications of the randomised models will be discussed in other planned future papers. We will provide analytical extensions that take into account imposed killing, leading to closedform formulas for specific exotic options under the randomised models. We will build a randomisation framework in a multi-asset economy and examine the analytical tractability of other complex derivatives for payoffs, depending on two or more assets.

\section{References}

Albanese, C., Campolieti, G., Carr, P., Lipton, A. (2001). Black-Scholes goes hypergeometric. Risk Magazine, 14(12), 99-103.

Black, F., \& Scholes M. (1973). The pricing of options and corporate liabilities. Journal of political economy, 81(3), 637-654.

Bollen, N.P. (1998). Valuing options in regime-switching models. Journal of Derivatives, 6, 38-50.

Campolieti, G., \& Makarov, R.N. (2012). On properties of analytically solvable families of local volatility diffusion models. Mathematical Finance: An International Journal of Mathematics, Statistics and Financial Economics, 22(3), 488-518.

Darsinos, T., \& Satchell, S. (2007). Bayesian analysis of the Black-Scholes option price. In S. Satchel, (Ed.), Forecasting Expected Returns in the Financial Markets (pp. 117-150). NY: Academic Press.

Hagan, P.S., Kumar, D., Lesniewski, A.S., \& Woodward, D.E. (2002). Managing smile risk. The Best of Wilmott, 1, 249-296.

Heston, S.L. (1993). A closed-form solution for options with stochastic volatility with applications to bond and currency options. The Review of Financial Studies, 6(2), 327-343.

Hull, J., \& White, A. (1987). The pricing of options on assets with stochastic volatilities. The Journal of Finance, $42(2)$, 281-300.

MacBeth, J. D., \& Merville, L. J. (1979). An empirical examination of the Black-Scholes call option pricing model. The Journal of Finance, 34(5), 1173-1186.

Prudnikov, A.P., Brychkov, I.A., \& Marichev, O.I. (1986). Integrals and series: special functions, vol. 2. CRC Press.

Renault, E., \& Touzi, N. (1996). Option hedging and implied volatilities in a stochastic volatility model. Mathematical Finance, 6(3), 279-302.

Rubinstein, M. (1985). Nonparametric tests of alternative option pricing models using all reported trades and quotes on the 30 most active CBOE option classes from August 23, 1976, through August 31, 1978. The Journal of Finance, $40(2), 455-480$.

Taleb, N.N. (2015). Unique option pricing measure with neither dynamic hedging nor complete markets. European Financial Management, 21(2), 228-235.

West, G. (2005). Calibration of the SABR model in illiquid markets. Applied Mathematical Finance, 12(4), 371-385, Wu, Q. (2012). Analytical Solutions of the SABR Stochastic Volatility Model. PhD dissertation. Columbia University. 
Table 1

Greeks of a European vanilla call option under randomisation

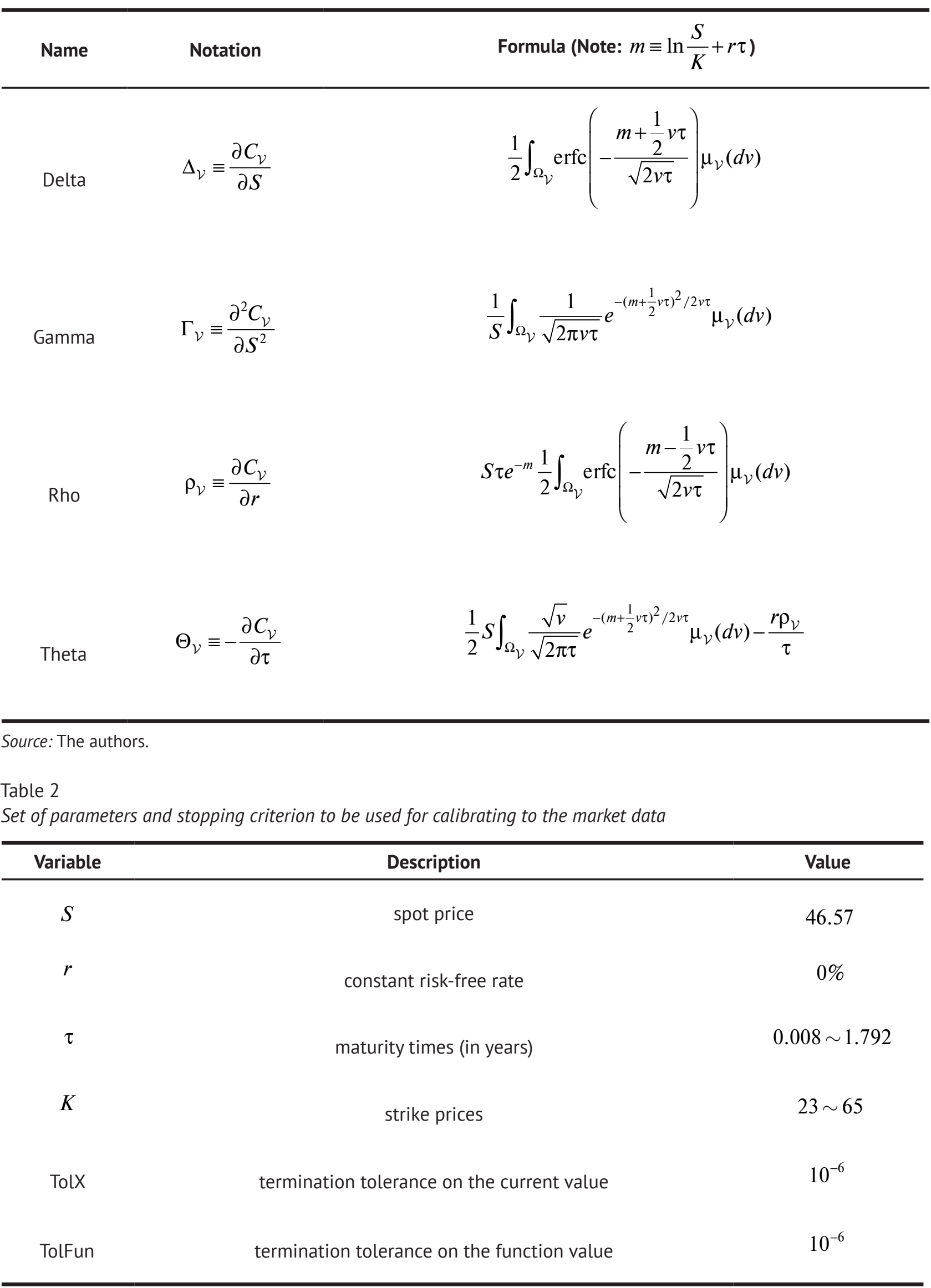

Source: The authors. 
Table 3

Optimal values of $\theta$ and $\lambda$ under the gamma randomisation (Note that we can only compare the RMSE with the inverse gamma randomisation for fixed $\tau$, but we cannot compare the RMSE across different values of $\tau$ because the sample size differs across maturity times)

\begin{tabular}{|c|c|c|c|c|c|}
\hline$\tau$ & $N_{\tau}$ & $\theta$ & $\lambda$ & RMSE & Time \\
\hline 0.008 & 33 & 0.095 & 0.575 & 0.041 & 71.194 \\
\hline 0.027 & 33 & 0.108 & 0.334 & 0.059 & 91.963 \\
\hline 0.044 & 35 & 0.176 & 0.171 & 0.070 & 8.189 \\
\hline 0.066 & 19 & 0.405 & 0.104 & 0.083 & 1.932 \\
\hline 0.085 & 15 & 0.214 & 0.215 & 0.159 & 3.123 \\
\hline 0.104 & 15 & 0.087 & 0.720 & 0.295 & 40.699 \\
\hline 0.123 & 24 & 0.193 & 0.228 & 0.121 & 5.902 \\
\hline 0.219 & 32 & 0.153 & 0.276 & 0.162 & 15.721 \\
\hline 0.373 & 31 & 0.369 & 0.089 & 0.169 & 4.230 \\
\hline 0.468 & 29 & 0.322 & 0.105 & 0.173 & 5.593 \\
\hline 0.622 & 24 & 0.482 & 0.067 & 0.175 & 3.156 \\
\hline 0.795 & 17 & 2.669 & 0.009 & 0.184 & 1.989 \\
\hline 1.216 & 16 & 3.245 & 0.007 & 0.186 & 1.837 \\
\hline 1.466 & 14 & 2.070 & 0.012 & 0.227 & 2.087 \\
\hline 1.792 & 17 & 11.021 & 0.002 & 0.173 & 2.154 \\
\hline
\end{tabular}


Table 4

Optimal values of $\theta$ and $\lambda$ under the inverse gamma randomisation (Note that we can only compare the RMSE with the gamma randomisation for fixed $\tau$, but we cannot compare the RMSE across different values of $\tau$ because the sample size differs across maturity times)

\begin{tabular}{|c|c|c|c|c|c|}
\hline$\tau$ & $N_{\tau}$ & $\theta$ & $\lambda$ & RMSE & Time \\
\hline 0.008 & 33 & 0.719 & 0.002 & 0.032 & 6.087 \\
\hline 0.027 & 33 & 0.827 & 0.002 & 0.051 & 3.460 \\
\hline 0.044 & 35 & 0.877 & 0.003 & 0.062 & 3.569 \\
\hline 0.066 & 19 & 1.227 & 0.014 & 0.079 & 2.332 \\
\hline 0.085 & 15 & 0.885 & 0.005 & 0.147 & 2.107 \\
\hline 0.104 & 15 & 0.672 & 0.002 & 0.280 & 2.533 \\
\hline 0.123 & 24 & 0.923 & 0.006 & 0.106 & 2.788 \\
\hline 0.219 & 32 & 0.799 & 0.003 & 0.135 & 3.897 \\
\hline 0.373 & 31 & 0.979 & 0.006 & 0.147 & 2.903 \\
\hline 0.468 & 29 & 0.926 & 0.005 & 0.141 & 3.787 \\
\hline 0.622 & 24 & 1.091 & 0.009 & 0.153 & 3.789 \\
\hline 0.795 & 17 & 2.406 & 0.035 & 0.181 & 2.338 \\
\hline 1.216 & 16 & 2.962 & 0.048 & 0.183 & 2.697 \\
\hline 1.466 & 14 & 1.861 & 0.024 & 0.217 & 2.310 \\
\hline 1.792 & 17 & 8.016 & 0.155 & 0.173 & 3.485 \\
\hline
\end{tabular}


Table 5

Optimal values of $\alpha, \sigma$ and $\rho$ under the SABR model (Note that we do not display the RMSEs here because the units associated from the SABR model is different from the randomised GBM models)

\begin{tabular}{|c|c|c|c|c|c|}
\hline$\tau$ & $N_{\tau}$ & $\alpha$ & $\sigma$ & $\rho$ & Time \\
\hline 0.008 & 33 & 21.729 & 2.994 & -0.502 & 0.435 \\
\hline 0.027 & 33 & 10.616 & 3.643 & -0.560 & 0.574 \\
\hline 0.044 & 35 & 7.711 & 4.204 & -0.619 & 0.353 \\
\hline 0.066 & 19 & 4.691 & 6.793 & -0.465 & 0.329 \\
\hline 0.085 & 15 & 5.040 & 6.239 & -0.610 & 0.341 \\
\hline 0.104 & 15 & 5.967 & 5.473 & -0.704 & 0.344 \\
\hline 0.123 & 24 & 3.633 & 6.119 & -0.570 & 0.337 \\
\hline 0.219 & 32 & 2.916 & 5.424 & -0.604 & 0.360 \\
\hline 0.373 & 31 & 1.895 & 5.701 & -0.535 & 0.159 \\
\hline 0.468 & 29 & 1.631 & 5.680 & -0.385 & 0.392 \\
\hline 0.622 & 24 & 1.147 & 6.256 & -0.341 & 0.378 \\
\hline 0.795 & 17 & 1.001 & 6.032 & -0.425 & 0.359 \\
\hline 1.216 & 16 & 0.673 & 6.272 & -0.242 & 0.371 \\
\hline 1.466 & 14 & 0.782 & 5.940 & -0.154 & 0.303 \\
\hline 1.792 & 17 & 0.467 & 6.371 & -0.058 & 0.331 \\
\hline
\end{tabular}

Source: The authors. 

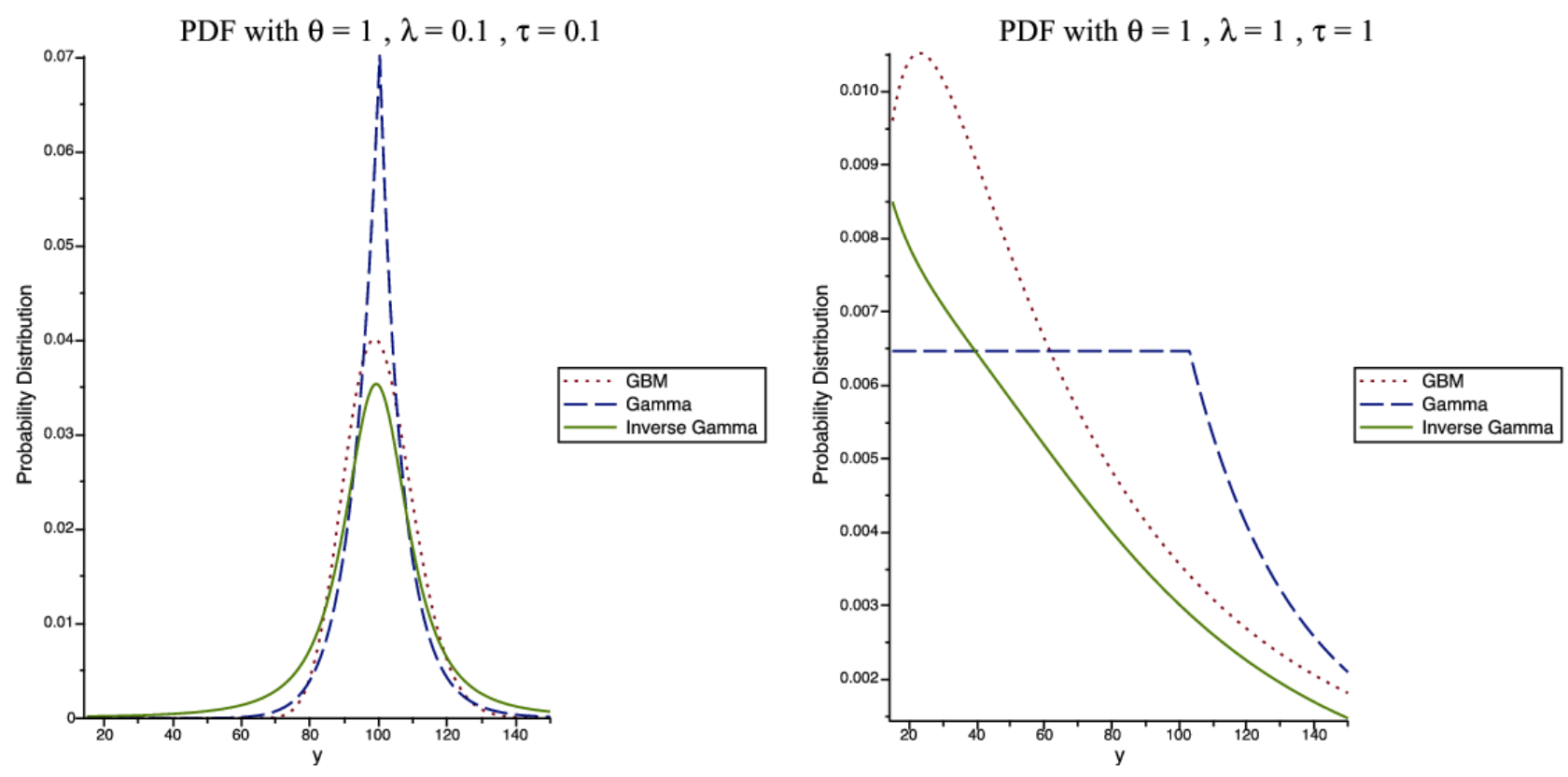

Figure 1. Plots of the transition PDFs for the process $S_{t}, S_{t}^{G(\theta, \lambda)}$, and $S_{t}^{I G(\theta, \lambda)}$, where $S=100, r=0.03$, and $v=0.1$

Source: The authors.
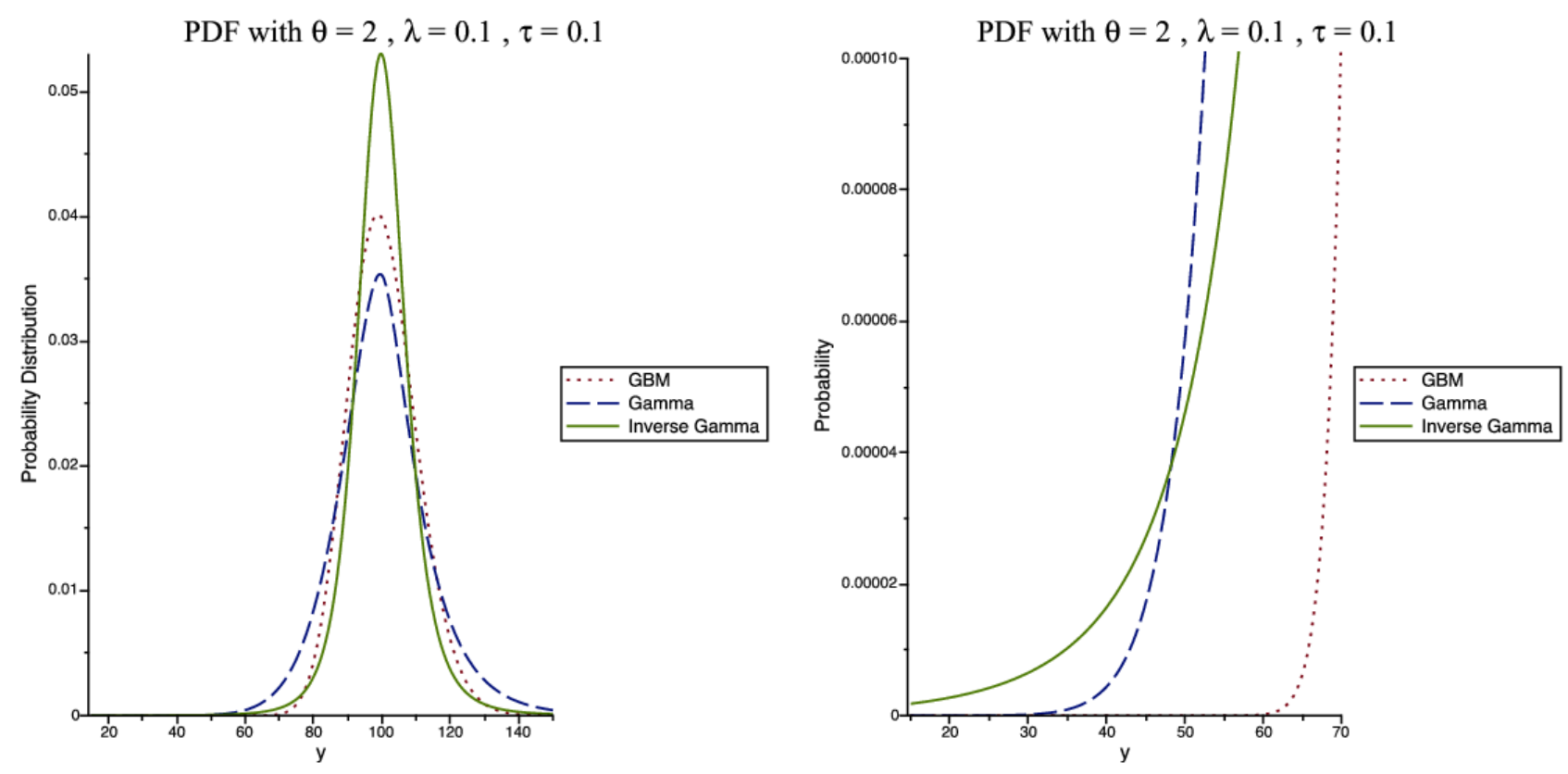

Figure 2. Plots of the transition PDFs for the process $S_{t}, S_{t}^{G(\theta, \lambda)}$, and $S_{t}^{I G(\theta, \lambda)}$, where $S=100, r=0.03$, and $v=0.1$

Source: The authors. 

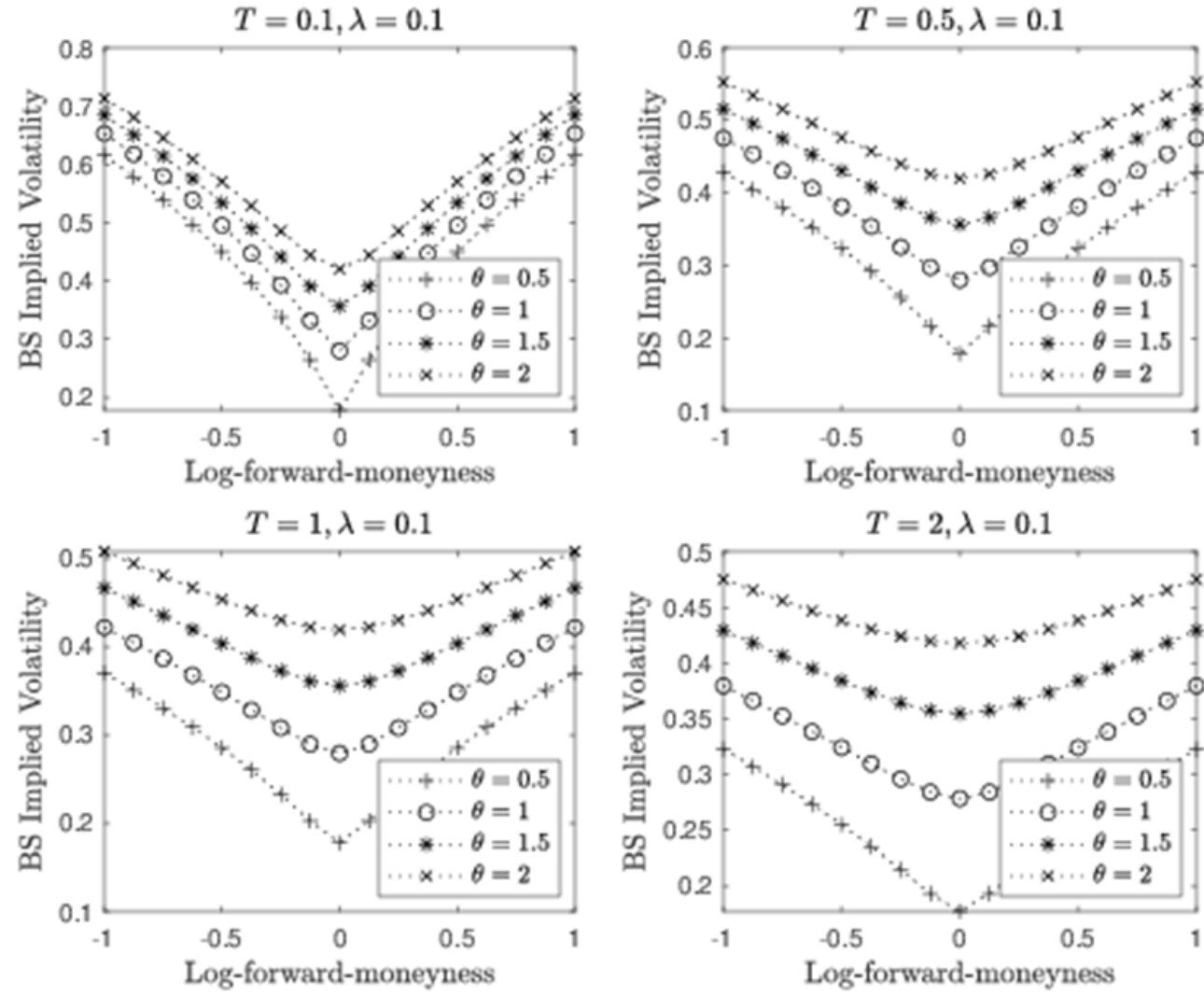

Figure 3. BS implied volatility of a European vanilla call option under the gamma randomisation Source: The authors.
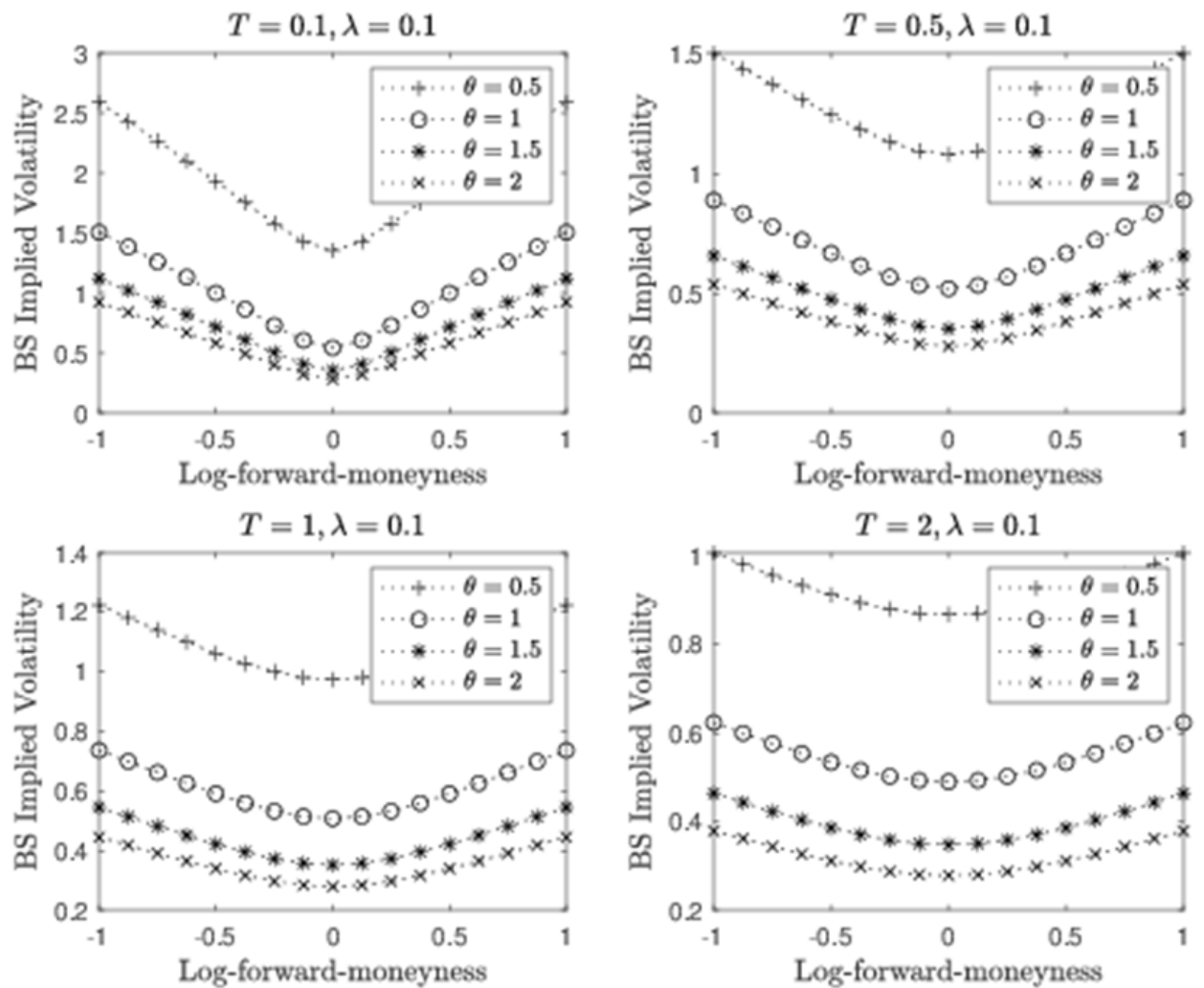

Figure 4. BS implied volatility of a European vanilla call option under the inverse gamma randomisation Source: The authors. 

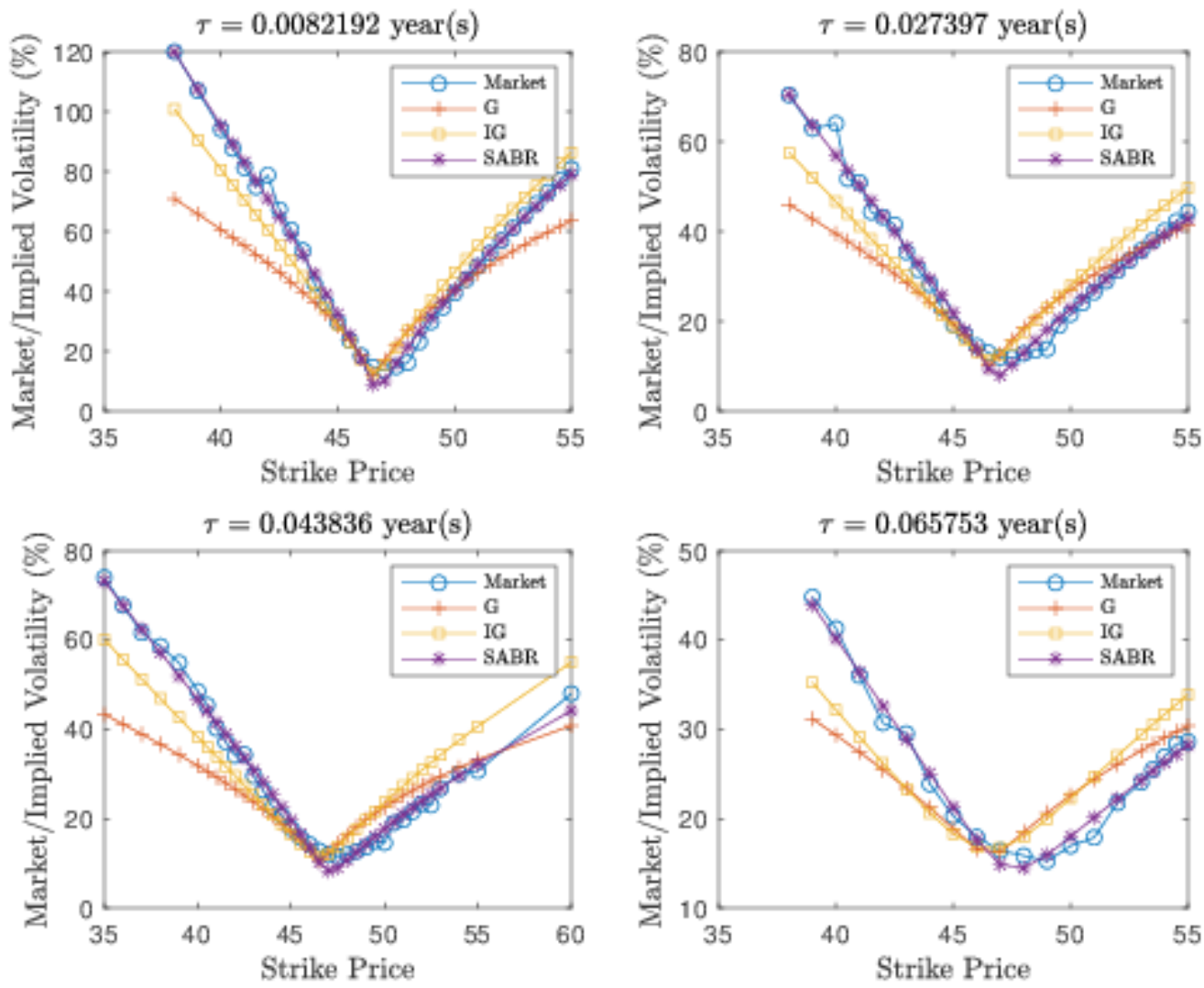

Figure 5. 2D Implied volatility plots for $\tau=0.008 \sim 0.066$ years

Source: The authors.
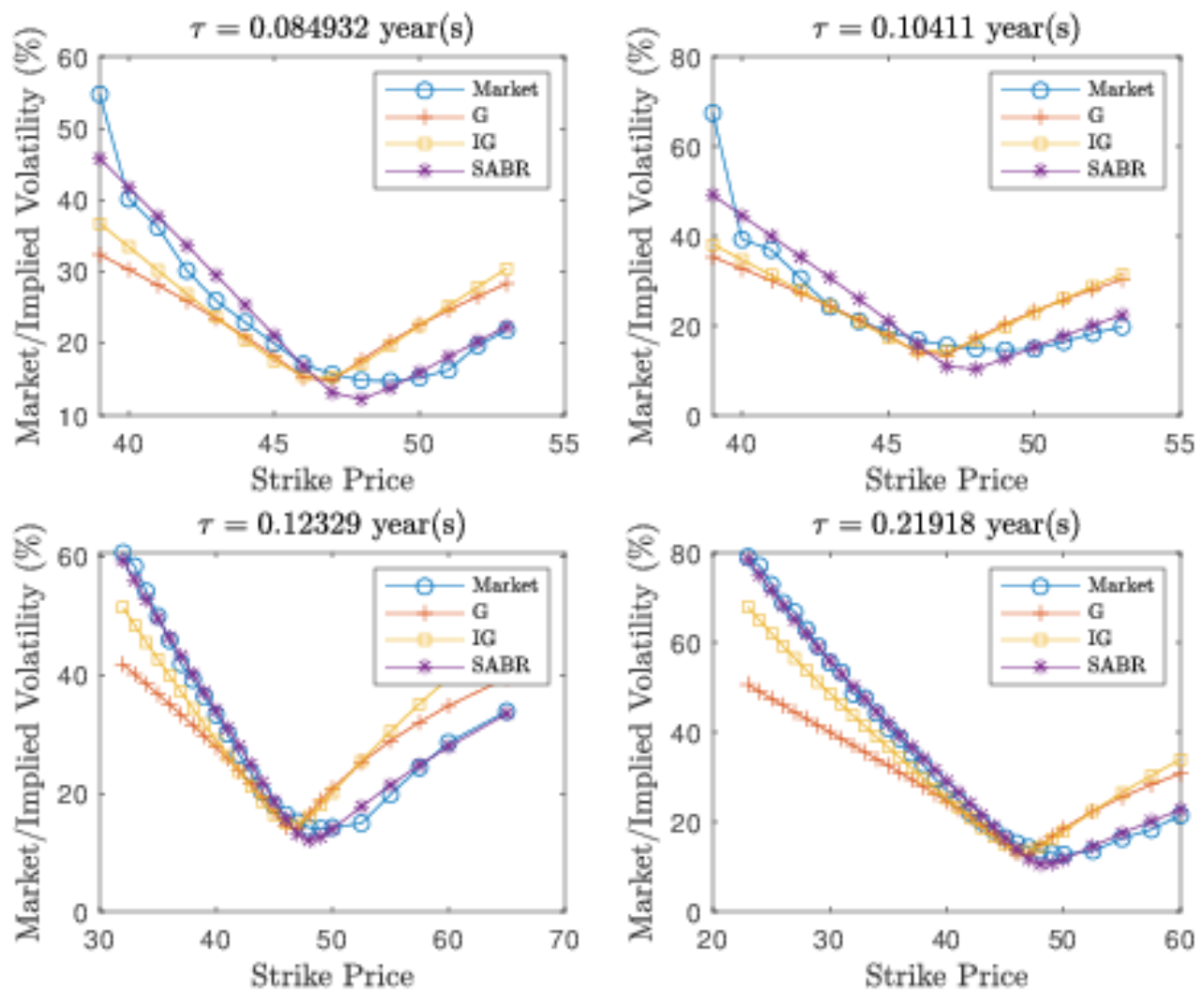

Figure 6. 2D Implied volatility plots for $\tau=0.085 \sim 0.219$ years

Source: The authors. 

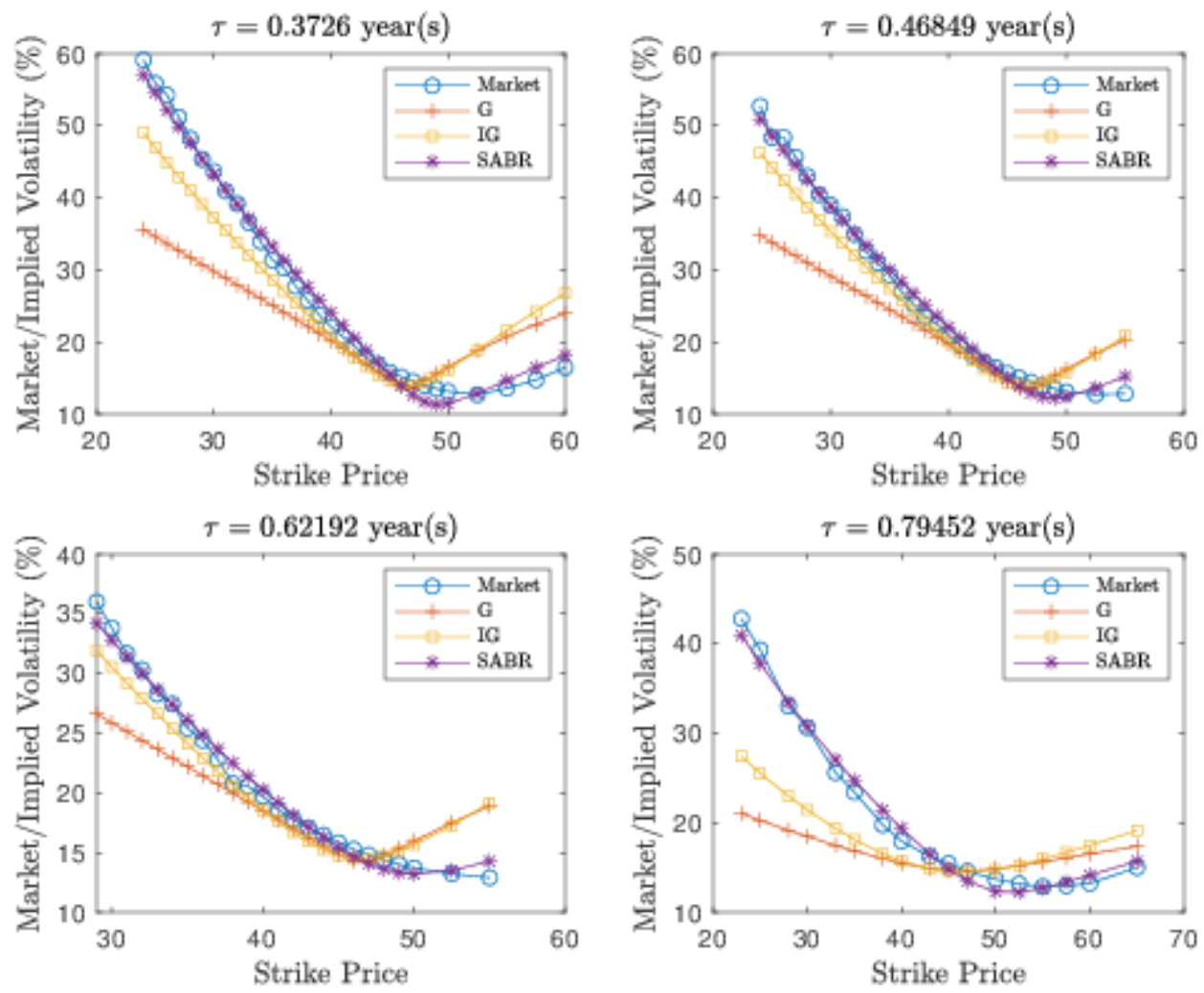

Figure 7.2D Implied volatility plots for $\tau=0.373 \sim 0.795$ years

Source: The authors.
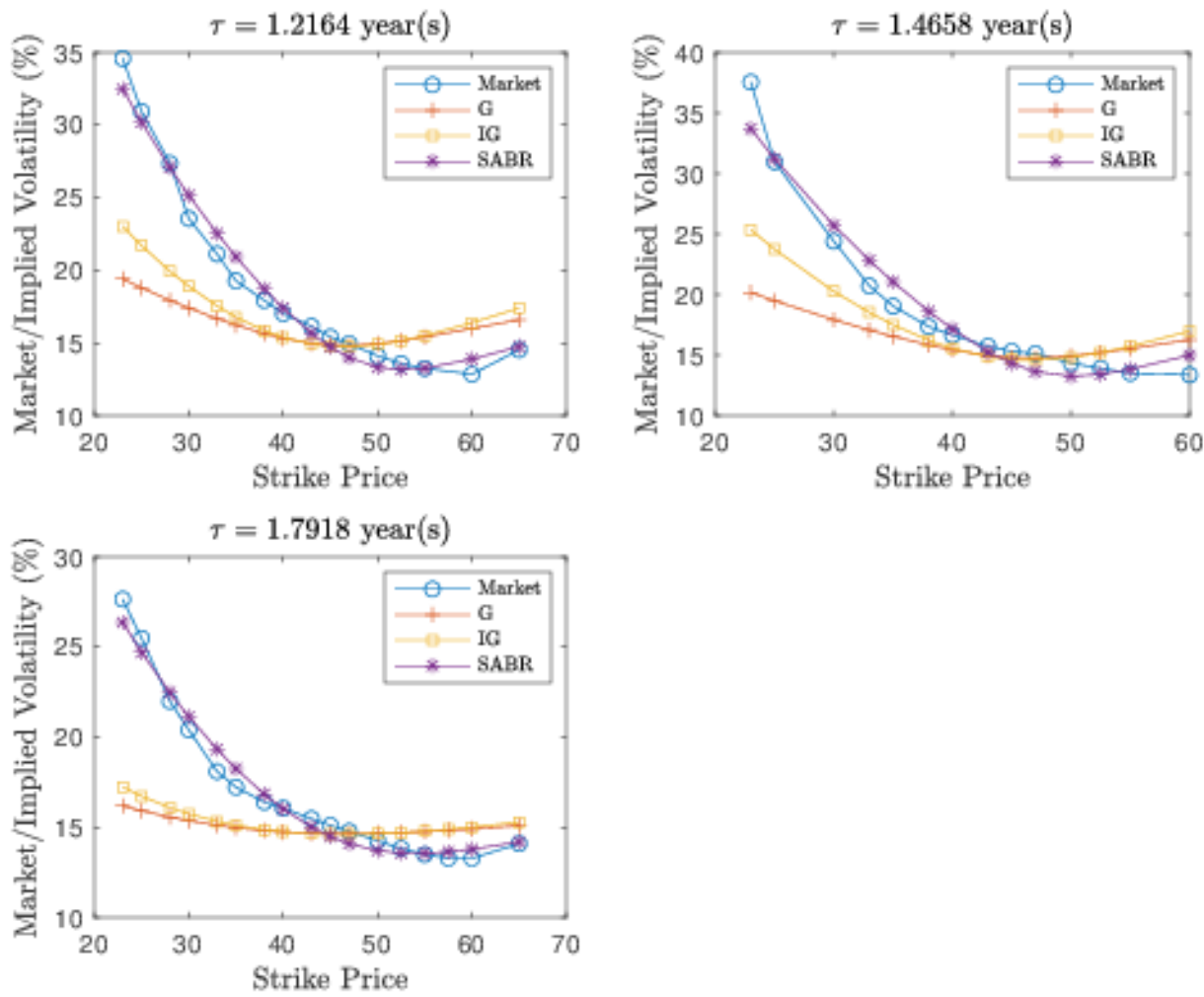

Figure 8. 2D Implied volatility plots for $\tau=1.216 \sim 1.792$ years

Source: The authors. 


\section{Appendix}

\section{A.1 Proof of the Exact Pricing Formula with Integer-valued Shape Parameter}

Let us take $\Lambda\left(S_{T}\right)=1_{\left\{S_{t}>K\right\}}$ with $K>0$, where $1_{\mathcal{A}}$ is the indicator function of some event $\mathcal{A}$. By (2) we have the following risk-neutral conditional probability that the asset price is above the strike $K$ at the time $T$ :

$$
\widetilde{\mathbb{P}}_{t, S}\left(S_{T}^{\mathcal{V}}>K\right)=\int_{\Omega_{\mathcal{V}}} \mathcal{N}\left(\frac{m-\frac{1}{2} v \tau}{\sqrt{v \tau}}\right) \mu_{\mathcal{V}}(d v)=\frac{1}{2} \int_{\Omega_{\mathcal{V}}} \operatorname{erfc}\left(-\frac{m-\frac{1}{2} v \tau}{\sqrt{2 v \tau}}\right) \mu_{\mathcal{V}}(d v)
$$

where erfc is the complementary error function. We state another useful integral formula (see Prudnikov, Brychkov, \& Marichev, 1986, Eq. 2.8.9.7): ${ }^{1}$

$$
\begin{aligned}
& \int_{0}^{\infty} x^{n} e^{-p x} \operatorname{erfc}\left(c \sqrt{x}+\frac{b}{\sqrt{x}}\right) d x=\frac{2(n) !}{p^{n+1}}\left\{1_{\{b<0\}}+\frac{\sqrt{|b|}\left(c^{2}+p\right)^{1 / 4}}{\sqrt{\pi}} e^{-2 b c} \sum_{k=0}^{n} \frac{p^{k}}{k !}\left(\frac{b^{2}}{c^{2}+p}\right)^{k / 2}\right. \\
& \left.\times\left[\operatorname{sgn}(b) \mathrm{K}_{k-1 / 2}\left(2|b| \sqrt{c^{2}+p}\right)-\frac{c}{\sqrt{c^{2}+p}} \mathrm{~K}_{k+1 / 2}\left(2|b| \sqrt{c^{2}+p}\right)\right]\right\},
\end{aligned}
$$

where $\operatorname{sgn}$ is the sign function with $\operatorname{sgn}(0)=1$. We can use (8) to obtain analytical formulas for the randomised processes in the case with integer-valued $\theta=n \in \mathbb{N}$. For the randomised $\mathrm{G}$ process, we have:

$$
\begin{aligned}
& \widetilde{\mathbb{P}}_{t, S}\left(S_{T}^{G(n, \lambda)}>K\right)=1_{\{m>0\}}-\frac{\sqrt{|m|}}{2 \sqrt{\pi}}\left(\frac{8+\lambda \tau}{\lambda \tau}\right)^{1 / 4} e^{m / 2} \sum_{k=0}^{n-1} \frac{1}{k !}\left(\frac{2|m|}{\sqrt{\lambda \tau} \sqrt{8+\lambda \tau}}\right)^{k} \\
& \times\left[\operatorname{sgn}(m) \mathrm{K}_{k-1 / 2}\left(\frac{|m|}{2} \frac{\sqrt{8+\lambda \tau}}{\sqrt{\lambda \tau}}\right)+\frac{\sqrt{\lambda \tau}}{\sqrt{8+\lambda \tau}} K_{k+1 / 2}\left(\frac{|m|}{2} \frac{\sqrt{8+\lambda \tau}}{\sqrt{\lambda \tau}}\right)\right] .
\end{aligned}
$$

For the randomised IG process, upon changing the integration variable, we have:

$$
\begin{aligned}
& \widetilde{\mathbb{P}}_{t, S}\left(S_{T}^{I G(n, \lambda)}>K\right)=\frac{\left(m^{2}+2 \lambda \tau\right)^{1 / 4}}{2 \sqrt{\pi}} e^{m / 2} \sum_{k=0}^{n-1} \frac{1}{k !}\left(\frac{\lambda \tau}{2 \sqrt{m^{2}+2 \lambda \tau}}\right)^{k} \\
& \times\left[\mathrm{K}_{k-1 / 2}\left(\frac{\sqrt{m^{2}+2 \lambda \tau}}{2}\right)+\frac{m}{\sqrt{m^{2}+2 \lambda \tau}} \mathrm{K}_{k+1 / 2}\left(\frac{\sqrt{m^{2}+2 \lambda \tau}}{2}\right)\right] .
\end{aligned}
$$

Now, we consider the risk-neutral conditional probability $\widehat{\mathbb{P}} \equiv \widetilde{\mathbb{P}}^{(S)}$ under an equivalent martingale measure with the asset price process $\left\{S_{t}\right\}_{t \geq 0}$ as the numéraire, where

$$
\widehat{\mathbb{P}}_{t, S}\left(S_{T}^{\mathcal{V}}>K\right) \equiv \widetilde{\mathbb{E}}_{t, S}\left[\frac{S_{T}^{\mathcal{\nu}} 1_{\left\{S_{T}^{\mathcal{V}}>K\right\}} / B_{T}}{S_{t}^{\mathcal{V}} / B_{t}}\right]=\frac{1}{2} \int_{\Omega_{\mathcal{V}}} \operatorname{erfc}\left(-\frac{m+\frac{1}{2} v \tau}{\sqrt{2 v \tau}}\right) \mu_{\mathcal{V}}(d v) .
$$

${ }^{1}$ The integral formula is valid for $\mathfrak{R}(p)>0,|\arg (c)|<\frac{\pi}{4}$. Moreover, it would be valid for $\mathfrak{R}\left(c^{2}+p\right)>0$ if $\mathfrak{R}(c)>0$. 
where $B_{t}=e^{r t}$ is the bank account value at the time $t$. For the randomised G process $\left\{S_{t}^{G(n, \lambda)}\right\}_{t \geq 0}, n \in \mathbb{N}$, by using (11) and (8), we have:

$$
\begin{aligned}
& \hat{\mathbb{P}}_{t, S}\left(S_{T}^{G(n, \lambda)}>K\right)=1_{\{m>0\}}-\frac{\sqrt{|m|}}{2 \sqrt{\pi}}\left(\frac{8+\lambda \tau}{\lambda \tau}\right)^{1 / 4} e^{-m / 2} \sum_{k=0}^{n-1} \frac{1}{k !}\left(\frac{2|m|}{\sqrt{\lambda \tau} \sqrt{8+\lambda \tau}}\right)^{k} \\
& \times\left[\operatorname{sgn}(m) \mathrm{K}_{k-1 / 2}\left(\frac{|m|}{2} \frac{\sqrt{8+\lambda \tau}}{\sqrt{\lambda \tau}}\right)-\frac{\sqrt{\lambda \tau}}{\sqrt{8+\lambda \tau}} K_{k+1 / 2}\left(\frac{|m|}{2} \frac{\sqrt{8+\lambda \tau}}{\sqrt{\lambda \tau}}\right)\right] .
\end{aligned}
$$

By substituting (9) and (12) into (5), we obtain (6). For the randomised IG process $\left\{S_{t}^{I G(n, \lambda)}\right\}_{t \geq 0}$, $n \in \mathbb{N}$, by using (11) and (8) we have:

$$
\begin{aligned}
& \hat{\mathbb{P}}_{t, S}\left(S_{T}^{I G(n, \lambda)}>K\right)=1-\frac{\left(m^{2}+2 \lambda \tau\right)^{1 / 4}}{2 \sqrt{\pi}} e^{-m / 2} \sum_{k=0}^{n-1} \frac{1}{k !}\left(\frac{\lambda \tau}{2 \sqrt{m^{2}+2 \lambda \tau}}\right)^{k} \\
& \times\left[\mathrm{K}_{k-1 / 2}\left(\frac{\sqrt{m^{2}+2 \lambda \tau}}{2}\right)-\frac{m}{\sqrt{m^{2}+2 \lambda \tau}} \mathrm{K}_{k+1 / 2}\left(\frac{\sqrt{m^{2}+2 \lambda \tau}}{2}\right)\right] .
\end{aligned}
$$

By substituting (10) and (13) into (5), we obtain (7).

\section{A.2 The Exact Pricing Formulas for ATMF Options}

The price of an ATMF (i.e., $m \equiv \ln (S / K)+r \tau=0$ ) European vanilla call option under the GBM model, with variance randomised according to the probability measure $\mu_{\mathcal{v}}$, can be expressed as:

$$
\widehat{C}_{\mathcal{V}}(\tau, 0)=\int_{\Omega_{\mathcal{V}}} \operatorname{erf}\left(\frac{\sqrt{v \tau}}{2 \sqrt{2}}\right) \mu_{\mathcal{V}}(d v)
$$

Where erf is the error function. We use the above equation to derive the pricing formulas for ATMF options explicitly under the gamma and inverse gamma randomisation for shape parameter $\theta \in \mathbb{R}_{+}$.

Proposition 1 The price (divided by spot $S$ ) of an ATMF European vanilla call option under the gamma randomisation is:

$$
\widehat{C}_{G(\theta, \lambda)}(\tau, 0)=1-\frac{\Gamma\left(\theta+\frac{1}{2}\right)}{\sqrt{\pi} \Gamma(\theta+1)}\left(\frac{8}{\lambda \tau}\right)^{\theta} \quad{ }_{2} \mathrm{~F}_{1}\left(\theta, \theta+\frac{1}{2} ; \theta+1,-\frac{8}{\lambda \tau}\right),
$$

where ${ }_{p} \mathrm{~F}_{q}(\mathbf{a} ; \mathbf{b} ; z)$ is the generalised hypergeometric function.

\section{Proof}

We first make a note that the incomplete gamma function can be expressed in terms of the Kummer function of the first kind.i.e.,

$$
\gamma(\theta, x)=\theta^{-1} x^{\theta} \quad{ }_{1} \mathrm{~F}_{1}(\theta ; \theta+1 ;-x) .
$$


Hence, we have

$$
\widehat{C}_{G(\theta, \lambda)}(\tau, 0)=1-\frac{1}{\sqrt{\pi} \Gamma(\theta+1)}\left(\frac{8}{\lambda \tau}\right)^{\theta} \int_{0}^{\infty}{ }_{1} F_{1}\left(\theta ; \theta+1 ;-\frac{8 y}{\lambda \tau}\right) y^{\theta-1 / 2} e^{-y} d y .
$$

And an integral representation of a generalised hyperbolic function is: ${ }^{2}$

$$
{ }_{p+1} \mathrm{~F}_{q}\left(\begin{array}{l}
a_{0}, \ldots, a_{p} \\
b_{1}, \ldots, b_{q}
\end{array} ; z\right)=\frac{1}{\Gamma\left(a_{0}\right)} \int_{0}^{\infty} s^{a_{0}-1} e^{-s}{ }_{p} \mathrm{~F}_{q}\left(\begin{array}{l}
a_{1}, \ldots, a_{p} \\
b_{1}, \ldots, b_{q}
\end{array} ; s\right) d s .
$$

From the integral representation above, we obtain the final expression.

Proposition 2 The price (divided by spot $S$ ) of an ATMF European vanilla call option under the inverse gamma randomisation is:

$$
\begin{aligned}
& \widehat{C}_{I G(\theta, \lambda)}(\tau, 0)=\sqrt{\frac{\lambda \tau}{2 \pi}} \frac{\Gamma\left(\theta-\frac{1}{2}\right)}{\Gamma(\theta)}{ }_{1} \mathrm{~F}_{2}\left(\frac{1}{2} ; \frac{3}{2}, \frac{3}{2}-\theta ; \frac{\lambda \tau}{8}\right) \\
& +\left(\frac{\lambda \tau}{8}\right)^{\theta} \frac{\Gamma\left(\frac{1}{2}-\theta\right)}{\sqrt{\pi} \Gamma(\theta+1)}{ }_{1} \mathrm{~F}_{2}\left(\theta ; \theta+1, \theta+\frac{1}{2} ; \frac{\lambda \tau}{8}\right) .
\end{aligned}
$$

\section{Proof}

We first make a note of an integral representation of the Kummer function of the first kind

$$
{ }_{1} \mathrm{~F}_{1}(a, b, c)=\frac{\Gamma(b)}{\Gamma(a) \Gamma(b-a)} \int_{0}^{1} e^{c u} u^{a-1}(1-u)^{b-a-1} d u .
$$

Hence, we have

$$
\widehat{C}_{I G(\theta, \lambda)}(\tau, 0)=\frac{2}{\sqrt{\pi} \Gamma(\theta)}\left(\frac{\lambda \tau}{8}\right)^{1 / 4+\theta / 2} \int_{0}^{1} u^{\theta / 2-3 / 4} K_{\theta-1 / 2}\left(\sqrt{\frac{\lambda \tau u}{2}}\right) d u
$$

Now use the fact that modified Bessel functions of the second kind can be expressed in terms of generalised hypergeometric functions.i.e.,

$$
\mathrm{K}_{\theta}(x)=\frac{\Gamma(\theta)}{2}\left(\frac{x}{2}\right)^{-\theta} \quad{ }_{0} \mathrm{~F}_{1}\left(;-\theta+1 ; \frac{x^{2}}{4}\right)+\frac{\Gamma(-\theta)}{2}\left(\frac{x}{2}\right)^{\theta} \quad{ }_{0} \mathrm{~F}_{1}\left(; \theta+1 ; \frac{x^{2}}{4}\right) .
$$

Another integral representation of a generalised hyperbolic function is: ${ }^{3}$

$$
{ }_{p+1} \mathrm{~F}_{q+1}\left(\begin{array}{l}
a_{0}, \ldots, a_{p} \\
b_{0}, \ldots, b_{q}
\end{array} ; z\right)=\frac{\Gamma\left(b_{0}\right)}{\Gamma\left(a_{0}\right) \Gamma\left(b_{0}-a_{0}\right)} \int_{0}^{1} s^{a_{0}-1}(1-s)^{b_{0}-a_{0}-1}{ }_{p} \mathrm{~F}_{q}\left(\begin{array}{l}
a_{1}, \ldots, a_{p} \\
b_{1}, \ldots, b_{q}
\end{array} ; s\right) d s
$$

From the integral representation above, we obtain the final expression.

\footnotetext{
${ }^{2}$ The integral formula is valid for $\Re(z)<1, \Re\left(a_{0}\right)>0$.

${ }^{3}$ The integral formula is valid for $\mathfrak{R}\left(b_{0}\right)>\Re\left(a_{0}\right)>0$.
} 


\section{ABOUT THE AUTHORS / ИНФОРМАЦИЯ ОБ АВТОРАХ}

Giuseppe (Joe) Campolieti - Professor at Graduate Faculty. He received PhD from McGill University in 1989. He joined Wilfrid Laurier University in 2002 as associate professor of Mathematics and as SHARCNET chair in Financial Mathematics. He also founded a financial software and consulting company in 1998.

Address: 75 University Ave W, Waterloo, ON, Canada

e-mail: gcampoli@wlu.ca

Джузеппе (Джо) Камполиети - Профессор. Получил докторскую степень в Университете Макгилла в 1989 г. В 2002 г. начал работу в Университете Уилфрида Лорье в качестве адъюнкт-профессора математики и кафедры финансовой математики SHARCNET. Университет Уилфрида Лорье, Ватерлоо, Онтарио, Канада

Hiromichi Kato - PhD student at Graduate Faculty (Mathematical and Statistical Modelling), Wilfrid Laurier University.

Address: 75 University Ave W, Waterloo, ON, Canada e-mail: kato4650@mylaurier.ca

Хиромити Като - аспирант в Университете Уилфрида Лорье на факультете аспирантуры. Университет Уилфрида Лорье, Ватерлоо, Онтарио, Канада

Roman Makarov - Associate Professor at Graduate Faculty; Chair, Mathematics. He received PhD in Computational Mathematics from the Russian Academy of Sciences in 2000. He joined Laurier in 2003.

Address: 75 University Ave W, Waterloo, ON, Canada

e-mail:rmakarov@wlu.ca

Роман Макаров - доцент факультета аспирантуры; кафедра математики. Получил докторскую степень по вычислительной математике в Российской академии наук в 2000 г. В 2003 г. начал работу в Университете Уилфрида Лорье. Университет Уилфрида Лорье, Ватерлоо, Онтарио, Канада

\section{Declared authors' contribution}

Giuseppe (Joe) Campolieti - concept and main theses of the article.

Hiromichi Kato - references, data mining.

Roman Makarov - computation, proofreading of formulas.

\section{Заявленный вклад авторов}

Джузеппе (Джо) Камполиети - концепция и основные тезисы статьи.

Хиромичи Като - ссылки, анализ данных.

Роман Макаров - вычисления, корректура формул.

The article was submitted on 17.05.2021, reviewed on 16.07.2021, and accepted for publication on 17.08.2021.

The authors read and approved the final version of the manuscript.

Статья поступила в редакцию 17.05.2021; после рецензирования 16.07.2021; принята к публикации 17.08.2021. Авторы прочитали и одобрили окончательный вариант рукописи. 